\title{
Abordagem bourdieusiana para uma análise de campo: um enfoque para a comunicação científica e o acesso aberto
}

\author{
Jackson da Silva Medeiros \\ Doutor; Universidade Federal do Rio Grande do Sul, Porto Alegre, RS, Brasil; \\ jackson.medeiros@ufrgs.br
}

\begin{abstract}
Resumo: O trabalho busca a compreensão de conceitos bourdieusianos, como campo, habitus e illusio, para empreender subsídios a reflexões relacionadas ao acesso ao conhecimento científico. Apresenta metodologia qualitativa e abordagem bibliográfica a partir, principalmente, das obras que tratam dos conceitos sistematizados por Pierre Bourdieu. Entende que as decisões no campo científico sempre envolvem a dualidade política e científica e que as escolhas feitas pelos agentes estão baseadas em interesses simbólicos. Encerra pautando o acesso aberto como uma possibilidade de se constituir como campo de barreira, impondo seus limites para que seja possível não aceitar influências externas, como a do capital econômico.
\end{abstract}

Palavras-chave: Pierre Bourdieu. Campo. habitus. illusio. Comunicação científica.

\section{Introdução}

Podemos compreender, à luz de Bourdieu, que há um comando na e da academia que, investido do poder simbólico que lhe é conferido, coordena as atividades científicas, isto é, todo um rol de recursos e ações que se engajam no fazer ciência, composto, entre outros elementos, pela definição de linhas de pesquisa e de locais de publicação, ou seja, pelo que é possível ou não pesquisar dentro de uma área e por quais canais a comunicação científica deve ser difundida. Isso se caracteriza em pilares tradicionais de conservadorismo das instituições, dos campos, espaços de disputa que mantêm um "[...] conjunto de mecanismos e procedimentos pelos quais [...] assegura[m] sua reprodução [...]" (BOURDIEU, 2004, p. 62). 
Assim sendo, o objetivo neste trabalho é a explicitação e a compreensão de conceitos bourdieusianos - campo, habitus, illusio - para arrolar subsídios a reflexões relacionadas ao acesso ao conhecimento científico. Para tal empreitada também buscamos outros autores, como Hannah Arendt, Cornelius Castoriadis, Patrice Bonnewitz, Omar Lizardo e Loïc Wacquant, com o intuito de locupletar as ideias do sociólogo francês.

A opção por trabalhar com conceitos apresentados por Pierre Bourdieu se pauta na caracterização operacional de suas propostas. Do mesmo modo que, antes de qualquer coisa, o sociólogo postula elementos funcionais, a reflexão aqui se utiliza desses procedimentos para compreender o que caracterizamos como crise no acesso às publicações científicas, ou, em uma breve determinação, uma tensão situada entre o acesso ou a restrição. Desse modo, não se trata de um trabalho analítico de casos concretos, mas com mote voltado ao como pensar conceitualmente as circunstâncias de pesquisas que advirão.

O trabalho, início de uma compreensão de conceitos que julgamos relevantes para estruturar a pesquisa desenvolvida com o intuito de investigar as bases teóricas, conceituais e metodológicas que dizem respeito à crise na circulação do conhecimento, está metodologicamente pautado em pesquisa qualitativa e abordagem bibliográfica a partir, principalmente, de obras - como A distinção: crítica social do julgamento (2006), Algumas propriedades dos campos (2003), O poder simbólico (2012), Os usos sociais da ciência: por uma sociologia clínica do campo científico (2004) e Razões práticas: sobre a teoria da ação (1996) - que tratam dos conceitos sistematizados por Pierre Bourdieu, agregando outros autores que possam contribuir para a temática em questão. Apresenta a seguinte estrutura: após esta introdução, os capítulos buscam aportes para contribuir às discussões sobre campo, habitus e illusio, bem como entender as perspectivas sobre o poder na atividade de comunicação científica. Em seguida são apresentadas as considerações finais e, por fim, são indicadas as referências utilizadas para a construção do artigo. 


\section{0 campo e as estruturas estruturantes}

Esta seção buscar elucidar elementos que permitam compreender a ideia de sociedade e de campo, bem como os conceitos conexos, como propostos por Bourdieu. Para tal, começaremos pela noção de poder simbólico, expressa no capítulo 1 do livro O poder simbólico (BOURDIEU, 2012), para levantar elementos sobre o tema. Buscamos, então, em um empreendimento epistemológico com diálogo entre comentadores de Bourdieu e autores que consideramos com ideias próximas e/ou complementares as do autor francês, um entendimento sobre o assunto, visando uma análise que permita compreensão sobre a reprodução da ordem social além do que há de relacional no campo.

Bourdieu caracteriza poder simbólico da seguinte maneira:

[...] poder invisível o qual só pode ser exercido com a cumplicidade daqueles que não querem saber que lhe estão sujeitos ou mesmo que o exercem. [...] é um poder de construção da realidade que tende a estabelecer uma ordem gnoseológica: o sentido imediato do mundo [...] supõe aquilo que Durkheim chama de conformismo lógico, quer dizer, 'uma concepção homogénea do tempo, do espaço, do número, da causa, que torna possível a concordância entre as inteligências'. [...] poder quase mágico que permite obter o equivalente daquilo que é obtido pela força (física ou económica), graças ao efeito específico de mobilização, só se exerce se for reconhecido, quer dizer, ignorado como arbitrário. (BOURDIEU, 2012, p. 7-15).

Esse continuum de caracterização do poder simbólico traz concepções interessantes para discussão. Chama atenção sua atuação a partir do que Bourdieu qualifica como cumplicidade, isto é, uma aceitação, em forma de interesse, daqueles que agenciam ou são agenciados no espaço. Nesse sentido, há uma estruturação propícia para que o poder simbólico atue, subsidiando recursos que o alimentam continuamente. Esses elementos têm função social de integração, mantendo, como percebe Bourdieu, um consensus sobre as determinações do mundo social; basicamente isso possibilita a reprodução de uma ordem já estabelecida e determinada pela vantagem que os indivíduos que conhecem o objeto têm sobre ele e sobre a organização.

É a classe dominante que define a hierarquização (taxonomia), determinando sua alteração, caso necessário, com vistas ao conservadorismo do poder existente. Também é responsável pela produção simbólica do que 
realmente está em jogo, do que importará, do que será alvo de seus interesses e do que os legitima (política) (BOURDIEU, 2012).

Esses agentes se distribuem a partir do capital que dispõem. A ideia de capital é originária da economia, mas aqui têm tipificações que vão além dessa compreensão. Pode ser (a) econômico propriamente dito, qualificado pela propriedade de bens econômicos; (b) cultural, que diz respeito às capacidades intelectuais; (c) social, indicado pela capacidade de uma entidade estabelecer relações sociais; e (d) simbólico, ligado ao reconhecimento que um agente tem a partir de seus pares (BONNEWITZ, 2003).

Indo por esse caminho, a estruturação da estrutura é formada pela ideologia que deve ser naturalizada e compartilhada por dominantes e dominados, e que, obviamente, serve a interesses dos seus produtores e de seus agentes. Assim, a heterogeneidade do campo, composto por agenciadores e agenciados, tem caráter de perpetuação da ideologia e, por consequência, da imposição de estruturas classificatórias.

É por isso que Bourdieu diz que o poder simbólico "[...] é uma forma transformada, quer dizer, irreconhecível, transfigurada e legitimada [...]" (BOURDIEU, 2012, p. 15). Mesmo que, se analisado, possa ser visto como uma deformação de estabilizações fundamentais do processo social, é incutido como uma forma originária e culturalmente aceita pelos membros que afetam e são afetados. Assim, sua atuação é fruto da ignorância, da desconsideração.

Com especial atenção ao termo culturalmente que articulamos no parágrafo anterior, Bourdieu se coloca em patamar que ultrapassa uma teoria antropológica da cognição partindo de uma negação da rígida sistematização proposta pelos antropólogos, uma vez que entende que o aparato cultural não é uma matriz imposta, fechada, com profunda coerência. Isso faz com que haja um processo de reconstrução de conceitualizações de experiências e de ações (LIZARDO, 2011).

Há nisso relação direta com Hannah Arendt na obra A condição humana quando a autora descreve que não é pela natureza que a condição humana é dada, mas pela ação de seus agentes, uma vez que os atores, em contato com outros elementos, fazem sua existência. Isso resulta que a produção humana é 
também o que condiciona o ser humano, criando o entendimento de que, apesar da propalada independência do homem, sua atuação tem por base os condicionamentos oriundos das relações (ARENDT, 2014).

A filósofa alemã vai mais longe ao discutir as questões entre o público e o privado e como isso se manifesta na sociedade e no sujeito, em uma compreensão da instauração de processos normalizadores:

Ao invés de ação, a sociedade espera de cada um de seus membros certos tipos de comportamento, impondo inúmeras e variadas regras, todas elas tendentes a 'normalizar' os seus membros, a fazêlos comportarem-se, a excluir a ação espontânea ou a façanha extraordinária. (ARENDT, 2014, p. 50).

Esse espaço é uma condição de existência do ser enquanto ser. É nessa esfera que suas condições são estabelecidas. Em outras palavras, podemos dizer que esse é um espaço de constantes lutas autorreguladas, uma vez que a manutenção desse espaço é autogerida. As condições de existência do espaço, criadas pelos agentes, são as condições de existência dos agentes que sofrem as forças ali existentes.

A condição humana compreende algo mais que as condições nas quais a vida foi dada ao homem. Os homens são seres condicionados: tudo aquilo com o qual eles entram em contato torna-se imediatamente uma condição de sua existência. O mundo no qual transcorre a vita activa consiste em coisas produzidas pelas atividades humanas; mas, constantemente, as coisas que devem sua existência exclusivamente aos homens também condicionam os seus autores humanos. Além das condições nas quais a vida é dada ao homem na Terra e, até certo ponto a partir delas, os homens constantemente criam as suas próprias condições que, a despeito de sua variabilidade e sua origem humana, possuem a mesma força condicionante das coisas naturais. [...] O impacto da realidade do mundo sobre a existência humana é sentido e recebido como força condicionante. A objetividade do mundo - o seu caráter de coisa ou objeto - e a condição humana complementam-se uma à outra. (ARENDT, 2014, p. 11-12).

Corneluis Castoriadis (1995, p. 354) explica uma ideia próxima em $A$ instituição imaginária da sociedade: “[...] é impossível desconhecer que o indivíduo social não se desenvolve como uma planta, mas é criado-fabricado pela sociedade [...]". Isto, segue o autor, é uma ruptura com o que considera como “[...] o estado primário da psique e suas exigências.”. Essa quebra forçada, 
violenta em essência, é o tipo de mal necessário, uma vez que demover o indivíduo do seu mundo é fazê-lo reconhecer a legitimidade do outro, caracterizando o sujeito não como produto finalizado, mas um resultado dos processos de socialização.

Significa dizer que contra um ente capaz de enxergar a si próprio como centro das atividades humanas - aquele indivíduo que Castoriadis busca explicação na psicanálise - e colocar-se como egoísta, é, na verdade, um ser capaz de se convencer que as regras do espaço são as naturalizadas, sendo as que devem ser seguidas. Dessa forma, a estruturação do espaço é infundida no indivíduo que se enxerga como um jogador.

Bourdieu (2004, p. 65) coloca essa percepção a partir do que intitula "[...] conversão coletiva [...]", ou seja, um tipo de reflexão sobre o ser enquanto ser no espaço em que atua ou deseja atuar; uma “[...] maneira de perceber os outros e de perceber a si mesmo.”. Há, nesse sentido, valências que atuam intraser, inter-ser e externa ao ser. Reconhecer o outro é o que Castoriadis chama de sublimação, isto é,

[...] o processo mediante o qual a psiquê é forçada a substituir seus 'objetos próprios' ou 'privados' de investimento [...] por objetos que são e valem na e pela imutituição (sic) social, e fazer para ela mesma, 'causas', 'meios' ou 'suportes' de prazer. (CASTORIADIS, 1995, p. 356).

Podemos afirmar então que há um descolamento do ser como composto inicialmente, uma vez que seus prazeres individuais sofrem uma socialização que o constitui, onde necessariamente percebe, de forma consciente ou inconsciente, que suas vontades e desejos não podem ser totalmente contemplados ou, ainda, que se constituem em nova forma de satisfação. Para isso o indivíduo se percebe como um agente que deseja ingressar no jogo, como em um ato de desinteresse, porque o espaço lhe oferece as condições e ele deve perceber no outro (nos outros agentes) a instituição de regras para atuação.

Seguindo na dialética entre Bourdieu e Castoriadis, o indivíduo está em uma posição de construtor e de construção, pensando nas ideias de um criador 


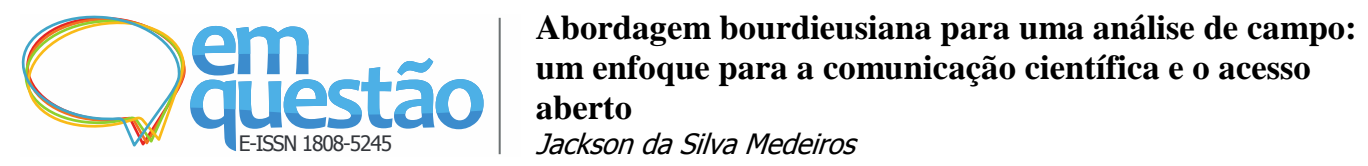

de elementos sociais e também afetado por eles. O agente é compreendido como um ser social.

O indivíduo social não pode ser constituído, 'objetivamente', a não ser mediante a referência a coisas e a outros indivíduos sociais, que ele próprio é incapaz de criar ontologicamente, porque eles só podem existir na e pela instituição; e ele é construído 'subjetivamente', na medida em que conseguiu fazer coisas e indivíduos para ele - ou seja, investir os resultados da instituição da sociedade. (CASTORIADIS, 1995, p. 359).

A lógica estabelecida advém da natureza enquanto fomentadoratransformadora do ser vivo. Quando (1) acontecimentos objetivos são transformados em acontecimentos (informação) para o ser vivo; quando (2) uma separação entre o que é acontecimento (informação) pertinente e não pertinente; e quando (3) dispositivos são colocados em ação, devendo ser atribuído o valor de informação pertinente (CASTORIADIS, 1995).

[...] cada sociedade particular é um autômato de tipo diferente, posto que (e na medida em que) estabelece um universo de discurso diferente, ou seja, posto que a instituição da sociedade estabelece cada vez, aquilo que, para a sociedade considerada é e não é, aquilo que é pertinente e aquilo que não é, o peso, o valor, a 'tradução' daquilo que é pertinente - e a 'resposta' correspondente. (CASTORIADIS, 1995, p. 273).

Estímulos ocorrem em todas as partes e o que garante a estruturação da ordem humana é o controle, artifício de regulação que permite e deixa de permitir, libera e proíbe sensações e pulsões. E a sociologia tem como uma de suas funções, de acordo com Bourdieu (1996, p. 141), “[...] determinar como o mundo social constitui a libido biológica, pulsão indiferenciada, em libido social, específica.”.

Na concepção de Bourdieu, essa estruturação é dada no campo, como estrutura, na qual se fundamenta o poder simbólico, ou seja, este faz parte da estruturação do que concebe como campo. Em síntese, o campo pode ser compreendido como

[...] o universo no qual estão inseridos os agentes e as instituições que produzem, reproduzem ou difundem a arte, a literatura ou a ciência. Esse universo é um mundo social como os outros, mas que 
obedece a leis sociais mais ou menos específicas. (BOURDIEU, 2004, p. 20).

Tomando essa ideia, campo, em sua acepção mais simples, é como um espaço virtual ${ }^{1}$ em que atores agenciam e são agenciados em um sistema que, a partir de suas leis, sistematiza práticas e regras que constroem e mantêm um jogo, sendo, nesse sentido, autônomo e independente do macrocosmo. Sua micro-existência responde a regramentos específicos, mas que prescindem, além de regras internas, das relações externas.

O campo é compreendido como um espaço que detém autonomia a partir das suas regras específicas, mas sofre com o disciplinamento que lhe é colocado pelo todo. Isso faz com que qualquer análise de um campo suscite dificuldade de estabelecimento do seu grau de autonomia, uma vez que diversos tipos de critérios são passíveis de compreensão como "[...] mecanismos que o microcosmo aciona para se libertar dessas imposições externas e ter condições de reconhecer apenas suas próprias determinações internas.” (BOURDIEU, 2004, p. 21).

Se a lógica do campo é a naturalização das regras do jogo, ou seja, das normas do campo, nada faz mais sentido do que os jogadores desse campo saibam jogar o jogo. Só aqueles que sabem jogar o jogo são capazes de se sustentar no campo. As conquistas do jogo só podem ser alcançadas quando se conhece as regras. É difícil imaginar um jogador de rugby que participe de um campeonato - e até mesmo o vença - com desconhecimento das regras do jogo.

Isso remete ao fato de que os campos são espaços de luta interna, mas também externas. A estruturação de um campo lhe permite estabelecer regras que regulam seu espaço interno e ao mesmo tempo impedem que fatores exteriores o atinjam. A razão do campo permite que haja uma refração; essa refração é reflexo do seu grau de autonomia (BOURDIEU, 2004).

No momento em que as regras impostas pelo campo são imputadas no indivíduo, é o próprio campo que faz a autorregulação das atividades que tentam adentrá-lo. Na ciência, por exemplo, pode haver um rechaçamento de métodos que não são comportados por aquele campo. Em outro exemplo, pode haver um 
expurgo, uma não aceitação de uma proposta que fuja às linhas de pesquisa previamente determinadas.

Essa ocorrência se dá porque as respostas de um campo estão dentro do próprio campo. Sua heterogeneidade faz parte de sua composição, não de uma possível pressão externa para que ele se modifique. Nesse sentido, a questão determinante da refração se dá por aquele campo que detém maior autonomia.

Claro que a constituição do campo atua de forma que a reunião de elementos heterogêneos forme esse conjunto. São esses elementos e suas propriedades que designam como se constitui o campo, criando um simbolismo que Castoriadis pensa no sentido do imaginário: “[...] por mais inacessíveis que sejam as significações imaginárias que sustentam esta organização [... é] possível que determinado objeto visível possua propriedades invisíveis [...]" (CASTORIADIS, 1995, p. 266).

Esses estratos naturalizados, como se refere Castoriadis, são tão vagos quanto persistentes; tão imprecisos quanto inelimináveis. Esse espaço virtual é a própria instituição do campo enquanto campo, da própria sociedade enquanto sociedade. Assim, os agentes se movem em um acordo tácito capaz de ser reconhecido apenas pelos players que ali atuam. A significação do campo só é compreendida pelos próprios atores do campo.

O encadeamento de elementos formadores e formados, em um complexo ir e vir de interações é o que instaura o ser a partir do campo e o campo a partir do ser. É “[...] um processo complexo que envolve interações sociais e o conjunto de influências e contingências recolhidas no percurso sociobiográfico de cada agente." (OLIVEIRA, 2005, p. 532). Isso implica que mesmo o campo não admitindo interferências externas, elas ocorrem, já que "existe uma homologia entre a estrutura social e os campos sociais." (BONNEWITZ, 2003, p. 62), fazendo com que determinações sociais idênticas atinjam campos diferentes.

Sabendo que "[...] as necessidades humanas, enquanto sociais e não simplesmente biológicas, são inseparáveis de seus objetos, e tanto umas quanto outros, instituídos a cada vez pela sociedade considerada" (CASTORIADIS, 1995, p. 205), isso se torna condizente com a relação do campo com o indivíduo 
e do indivíduo com o campo, sob o prisma do estabelecimento de relações do que se quer alcançar e do que é oferecido. Ou como aponta Arendt (2014, p. 12), "por ser uma existência condicionada, a existência humana seria impossível sem as coisas, e estas seriam um amontoado de artigos incoerentes, um não-mundo, se esses artigos não fossem condicionantes da existência humana.".

Essa capacidade de estruturação do campo pode ser "[...] determinada pela distribuição do capital científico num dado momento." (BOURDIEU, 2004, p. 24). Os agentes utilizam-se de seus lugares no próprio campo para determinar a condição de existência do campo. Os detentores de maior capital colocam sua carga em objetivos próprios ou para determinação do espaço. A partir disso, as estratégias de avanço no acúmulo de capital são traçadas.

O capital que os agentes têm à sua disposição não é criado por eles mesmos, mas pelo reconhecimento que é advindo dos pares, sempre concorrentes, que agem dentro do campo. Ou seja, o campo é um espaço de luta perversa, onde agentes são concorrentes ao mesmo tempo em que são incitadores positivos de outros. "A razão dessas lutas é a acumulação de capital que garante a dominação do campo.” (BONNEWITZ, 2003, p. 60-61).

Dessa forma, as questões que circunscrevem o campo são reguladas pelo próprio campo; o que é legítimo do campo está colocado no arrolamento de ocorrências do campo, e só o campo - entenda-se os portadores de poder simbólico no campo, os dominantes - são capazes de legalizar as propostas recebidas. São eles - os dominantes - que garantem ao campo sua coesão e quais temas podem ser tratados e reconhecidos.

Outra questão importante a ser tratada é que a conservação de determinada ordem social carrega uma série de estratégias; estas são responsáveis por manter ou melhorar a posição social dos dominantes através do investimento biológico: regulação do número de descendentes-membros do campo; da sucessão: transmissão do poder e do capital com a menor perda possível; da educação: fornecendo um tipo de formação que assegure a "qualidade" dos sucessores; da economia: onde a acumulação de capital econômica e social permite a manutenção de relações sociais; do simbólico: 
conservação e aumento do reconhecimento social no/do campo (BONNEWITZ, 2003).

Vejamos: pesquisadores que atuam no mesmo campo científico, por exemplo, disputam o reconhecimento de outros a partir de seu conhecimento difundido. No campo científico, em geral, a primeira publicação sobre uma descoberta detém os créditos (reconhecimento) para seu autor. Ora, a disputa se cristaliza desde esse momento em virtude da possibilidade de reconhecimento pelo feito, o que só pode ser promulgado, em primeira instância, a partir da aceitação por pares concorrentes que aferem o caráter de conhecimento científico válido àquilo que foi publicado. Após, com a multiplicação do conhecimento registrado, outros pares entram em cena, aceitando aquele conhecimento como relevante e também fazendo sua divulgação, o que ocorre, geralmente, a partir de citações.

\section{Elementos do campo: habitus, illusio}

Em uma aproximação com o conceito de conatus, de Baruch Spinoza, Pierre Bourdieu projeta uma operacionalização da naturalidade da afetividade. É a potência de agir do ser, aquilo que lhe traz felicidade e que está ligada aos afetos, em um sentido de permanência e aprimoramento, através da busca de estratégias para a reprodução da ordem social.

É da relação existente entre a estruturação social e a intencionalidade dos indivíduos que Bourdieu projeta a ideia de habitus. A questão é que cada campo define seus valores e os pesos desses valores a partir de regras que não têm uma verticalidade ou horizontalidade definida. A compreensão do que é informação pertinente em determinado campo é um acordo tácito que apenas os iniciados nesse campo são capazes de compreender.

Indo mais além: os próprios valores que o campo sustenta e que o sustentam são de difícil apreensão. Esses “[...] valores são coisas ou maneiras de ser considerados como estimáveis e desejáveis, ideais mais ou menos formalizados que orientam as ações e os comportamentos de uma sociedade ou de um grupo social" (BONNEWITZ, 2003, p. 76). Para Bourdieu, essa 
socialização de valores é regida pelo habitus, em uma tentativa de explicar como as ações humanas são padronizadamente controladas sem que haja imposição explícita.

O habitus se caracteriza pelas "[...] maneiras de ser permanentes [... no] campo.” (BOURDIEU, 2004, p. 28). Ou seja, é uma percepção da interiorização que o campo influencia o agente, fazendo com que se constitua em "[...] um mecanismo essencial de socialização, na medida em que os comportamentos e valores aprendidos são considerados como óbvios, como naturais, como quase instintivos" (BONNEWITZ, 2003, p. 77). A durabilidade naturalizada dos valores, das metas, das proposições é o que caracteriza o habitus como um espaço de disposições.

Essa durabilidade de valores, a caracterização do habitus, é mantida por todos aqueles que participam do campo. A luta, a disputa, e mesmo a subversão dentro do campo, contribuem para a reprodução da ordem social estabelecida, uma vez que se há disputa, o valor do que está sendo disputado é reconhecido (BOURDIEU, 2003).

É importante que pensemos no habitus como "[...] uma estrutura interna sempre em via de reestruturação. [...] nossas práticas e representações não são nem totalmente determinadas [...], nem totalmente livres [...]" (BONNEWITZ, 2003, p. 79). Esse processo está baseado na “[...] história individual e grupal sedimentada no corpo, estrutura social tornada estrutura mental [...]" (WACQUANT, 2007, p. 66). Pensando dessa maneira, há uma relação direta entre o habitus e o campo que Bourdieu define como inconsciente. Ou, poderíamos inferir, culturalmente estabelecida, como vimos.

O habitus, sistema de disposições adquiridas pela aprendizagem implícita ou explícita que funciona como um sistema de esquemas geradores, é gerador de estratégias que podem estar objectivamente em conformidade com os interesses objectivos dos seus autores sem terem sido expressamente concebidos para esse fim. (BOURDIEU, 2003, p. 125).

Löic Wacquant (2007, p. 66) diz que esse conceito remete à maneira “[...] como a sociedade torna-se depositada nas pessoas sob a forma de disposições duráveis ou capacidades treinadas e propensões estruturadas para 
pensar, sentir e agir de modos determinados [...]". Isso possibilita perceber de forma mais clara o que vimos trabalhando, ou seja, um processo de internalização das conceitualizações que o campo engendra em um curso de naturalização social que o campo emana para seus agentes. Quer dizer, a relação do habitus com o campo compõe o próprio campo como substrato culturalmente internalizado (aprendido/apreendido) pelos agentes. Assim, “[...] o mais importante é, sem dúvida, que a questão desse espaço é formulada nesse mesmo espaço" (BOURDIEU, 2006, p. 162).

O habitus fornece, ao mesmo tempo, um princípio de sociação e de individuação: sociação porque nossas categorias de juízo e de ação, vindas da sociedade, são partilhadas por todos aqueles que foram submetidos a condições e condicionamentos sociais similares (assim, podemos falar de um habitus masculino, de um habitus nacional, de um habitus burguês etc.); individuação porque cada pessoa, tendo uma trajetória e uma localização únicas no mundo, internaliza uma combinação incomparável de esquemas. Por ser simultaneamente estruturado (por meios sociais passados) e estruturante (de ações e representações presentes). (WACQUANT, 2007, p. 67-68).

O indivíduo não é um indivíduo cru, destituído de socializações. É, sim, um sujeito, subjetivado. O que existem são variações de habitus. Variações essas que são oriundas da vivência do ser, dos valores que foram provocados em um ser que sofreu um processo de socialização e de naturalização de maneiras de pensar e de agir a partir de experiências pregressas regidas pelo jogo. Conforme Bourdieu (2006, p. 162): “o habitus é, com efeito, princípio gerador de práticas objetivamente classificáveis e, ao mesmo tempo, sistema de classificação [...] de tais práticas.".

A cada classe de posições corresponde uma classe de habitus (ou de gostos) produzidos pelos condicionamentos sociais associados à condição correspondente e, pela intermediação do habitus e de suas capacidades geradoras, um conjunto sistemático de bens e propriedades, vinculadas entre si por uma afinidade de estilo. [...] O habitus é esse princípio gerador e unificador que retraduz as características intrínsecas e relacionais de uma posição em um estilo de vida unívoco, isto é, em um conjunto unívoco de escolhas de pessoas, de bens, de práticas. (BOURDIEU, 1996, p. 21-22). 
Outro conceito bourdieusiano que julgamos relevante para este estudo, embora pouco explorado na literatura, é illusio. Bourdieu (2004, p. 30) sintetiza a ideia como "[...] a crença científica como interesse desinteressado e interesse pelo desinteresse [...]". Esse conceito nasce a partir da ideia que os interesses perseguidos devem ser vistos pelos próprios agentes/campos como significativos. Assim, o que existe é um tipo de jogo que é jogado no campo por seus agentes com um senso de pertencimento àquele jogo, carregado sem a devida ponderação pelos membros do campo.

\begin{abstract}
Lembrar que os jogos intelectuais também têm alvos, que esses alvos suscitam interesses - coisas que de certo modo todos sabem é tentar estender a todas as condutas humanas, aí compreendidas as que se apresentam ou são vividas como desinteressadas, o modo de explicação e de compreensão de aplicação universal que define a visão científica, e arranca o mundo intelectual do estatuto de exceção ou de extraterritorialidade que os intelectuais têm tendência de lhe atribuir. (BOURDIEU, 1996, p. 137-138).
\end{abstract}

Sendo assim, illusio significa uma estadia e continuação no campo, acreditando que ali estar vale a pena. É estar em relação direta com o entendimento da importância do jogo que ali é jogado. É o reconhecimento da estrutura colocada pelo habitus. A naturalização do jogo, regida pelo habitus, infere na cumplicidade sobre as estruturas do campo. A relação tácita é aqui quase explícita, uma vez que illusio, mesmo que permita o contraponto de estruturas já colocadas pelo habitus, só existe se há concordância com a pertinência do que está em jogo (BOURDIEU, 1996).

Como percebe Oliveira (2005, p. 538) ao observar os escritos de Bourdieu, a ideia de illusio é uma clara relação da perspectiva social da pulsão, ou seja, uma análise sociológica da visão psicanalítica, já que estas são “[...] perspectivas reciprocamente auxiliares e uma jamais prescinde da outra quando se trata de investigar a emergência e a constituição da illusio nos agentes.”.

[...] o trabalho de socialização da libido é, precisamente, o que transforma as pulsões em interesses específicos, interesses socialmente constituídos que apenas existem na relação com um espaço social no interior do qual certas coisas são importantes e outras são indiferentes, para os agentes socializados, constituídos de maneira a criar diferenças correspondentes às diferenças objetivas nesse espaço. (BOURDIEU, 1996, p. 141-142). 
Compreender que illusio é uma "Estrutura aberta que se refaz transformando-se, a mônada psíquica é a usina das elaborações imaginárias que se manifesta em illusios, em apostas, crenças, símbolos, fantasias." (OLIVEIRA, 2005, p. 540), possibilita assimilar que os alvos a serem conquistados são, como já anotamos, uma forma de estruturar a busca constante pela recompensa e pela manutenção do campo. Ou seja, o campo se mantém estruturado com a constante vontade de perseguir, de alcançar; criar novas motivações e, novamente, perseguir e alcançar.

Exemplificando no campo científico: a articulação - atingindo principalmente os recém-chegados - de que fazer ciência é impor a neutralidade e deixar seus interesses de lado em prol dos interesses de um campo e até da sociedade reflete o ato de desinteresse. É compreender que a ciência é um jogo de desinteressados no reconhecimento e na posição mais alta do campo. É, reduzindo a uma expressão comentada de Bourdieu, o estabelecimento do cinismo.

Juntemos a isso, para o campo científico, a própria ideia de ciência ${ }^{2}$. O resultado, na ciência, é o que se deseja ao realizar uma investigação, mas o que o campo científico julga e autorregula são “[...] os princípios de verificação da conformidade do 'real', acerca dos métodos comuns de validação de teses e de hipóteses [...]" (BOURDIEU, 2004, p. 33). Sendo assim, a preocupação da ciência em descobrir uma verdade não está (ou não deveria estar, especulamos) colocada no resultado final como verdade instituída, mas na sistemática, no método, na instrumentalização que foi utilizada para se chegar às argumentações e/ou análises finais.

Os parágrafos acima mostram um envolvimento do capital científico político - temporal -, aquele ligado à posição do agente em instituições, o qual implica no poder de produção e reprodução, e do capital científico específico, ligado ao reconhecimento. O primeiro advém de atitudes estratégicas políticas; já o segundo é um tipo puro, adquirido pela contribuição ao(s) campo(s) de atuação. Nesse bojo que opera a necessidade percebida pelos novatos em um 
campo de se utilizar dos que já mantêm algum tipo de prestígio - seja por reconhecimento, seja por política - como alavancas.

\section{Perspectivas para compreender o poder na atividade de comunicação científica}

O que buscamos com este trabalho é a construção de um arcabouço teórico e conceitual que, embora não completamente expresso aqui por questões de formato, presume "[...] que os agentes sociais não realizam atos gratuitos." (BOURDIEU, 1996, p. 138). Nesse sentido, a procura pela razão de tais atos, como a publicação em periódicos científicos, é uma busca com intuito específico e estratégico.

Bourdieu ensina sobre a importância da observação do que rege os acontecimentos, buscando uma compreensão das determinações não casuísticas do campo:

[...] para a reflexão prática, o que comanda os pontos de vista, o que comanda as intervenções científicas, os lugares de publicação, os temas que escolhemos, os objetos pelos quais nos interessamos etc. é a estrutura das relações objetivas entre os diferentes agentes que são [...] os princípios do campo. É a estrutura das relações objetivas entre os agentes que determina o que eles podem e não podem fazer. (BOURDIEU, 2004, p. 23).

Por essa linha, sabendo do grande potencial de difusão dos periódicos científicos sustentados pelos conglomerados editoriais, a ideia de publicar em periódicos de acesso aberto cria uma condição de desestabilização daqueles que detêm o poder da editoração. No entanto, é uma luta constante, já que as revistas com alto Fator de Impacto (FI) estão, em geral, diretamente ligadas aos editores científicos que cobram pelo acesso ao conhecimento científico. Nesse caso, apropriando-se da ideia de campo, a vantagem - se assim podemos nos referir é que “[...] o campo é um jogo no qual as regras do jogo estão elas próprias postas em jogo [...]" (BOURDIEU, 2004, p. 29). 
Entra em cena um motor desse processo, como proposto por Eugene Garfield, isto é, o Fator de Impacto (FI), em uma visão onde a comunicação está baseada em fatores quantitativos. Esse é um tipo de

[...] indicador utilizado para calcular o número médio de citações recebidas por uma revista científica e é obtido com base na relação entre o número de vezes que a revista foi citada e o número de artigos que ela publicou num determinado período de tempo [...]. (VANTI; COSTA; SILVA, 2013, p. 229).

Se compreendermos, como Bourdieu (2004) aponta, que a relação de um campo a fatores externos, ou seja, seu poder de refração, é dada pela sua capacidade de autonomia, devemos considerar que o capital financeiro atinge o campo da comunicação científica, como qualquer outro, de forma decisiva. Há, por exemplo, a imposição de conglomerados editorias que forçam determinados campos a depender de suas proposições, uma vez que detêm condições de subsidiar processos editoriais muito mais complexos e pesados do que na analogia que possa ser feita com periódicos científicos de acesso aberto, os quais, em geral, são administrados por entidades educacionais e/ou instituições públicas.

Em suma, a partir do momento em que o indivíduo prepara sua comunicação, a possibilidade de publicar em periódicos melhores avaliados o coloca, assim entendemos, em um processo em que o habitus, também podendo ser aqui caracterizado como estratégia, permite pleitear a conquista de uma posição almejada. Para aqueles que já dispõem de alto capital científico, conservar sua posição, mantendo a situação de dominador no campo com o capital específico já adquirido.

O campo fornece a possibilidade de luta constante, tanto por parte dos já empoderados quanto por parte do que desejam o empoderamento. Cada um disputa essa luta a partir das armas que dispõe, do seu capital específico em busca da manutenção ou do alcance do poder simbólico. A manutenção ou a subversão do campo é uma condição que agentes tentam estabelecer a partir da posição que ocupam. 
A própria concepção de habitus é extremamente profícua se pensarmos diretamente na relação com a publicação de pesquisas quando se está lidando com a relação entre acesso aberto e acesso fechado. Para Bourdieu, o habitus permite que seja possível estabelecer uma resistência à estrutura do campo, uma vez que a não aceitação das disposições impostas faz com que esses atores subversivos estejam constantemente em processo de deslocamento e mal ancorados nele, compondo uma constante luta contra a sistemática da estrutura já ordenada e reproduzida pelo campo.

\footnotetext{
Os que, num estado determinado de relação de força, monopolizam (mais ou menos completamente) o capital específico, fundamento do poder ou da autoridade específica característica de um campo, inclinam-se para estratégias de conservação - as que [...] tendem para a defesa da ortodoxia -, ao passo que os menos providos de capital [...] inclinam-se para as estratégias de subversão - as de heresia. É a heresia, a heterodoxia, enquanto ruptura crítica, muitas vezes ligada à crise, com a doxa, que faz sair os dominantes do silêncio e que lhes impõe que produzam o discurso defensivo da ortodoxia, pensamento direito e de direita, visando restaurar o equivalente da adesão silenciosa da doxa. (BOURDIEU, 2003, p. 121).
}

Tomando essas considerações a partir do campo científico, a atividade de publicar está no centro da ciência. A atividade mais nobre da ciência é a divulgação, a publicação dos resultados alcançados, promovendo a difusão da descoberta e, por conseguinte, o avanço científico. O valor da pesquisa se dá a partir de sua comunicação, com avanços para a ciência em si e para a sociedade ${ }^{3}$.

Nesse sentido a relação é direta. Para haver reconhecimento científico, determinado autor necessita ser citado por seus pares. Essas citações, ou seja, as relações, para além do significado textual, entre o trabalho produzido e o trabalho utilizado como fonte, como fundamentação, são um tipo de contagem que indica a visibilidade do acadêmico no seu campo de atuação. Para atingir o maior número de indivíduos que possam ter interesse em um trabalho, nada mais natural e naturalizado que a publicação seja realizada em um periódico de grande difusão e que os trabalhos que lá sejam publicados tenham a chancela de "trabalhos de qualidade", uma vez que passam por severos crivos avaliativos. 
No entanto, há de se levar em consideração que esse é o caminho do habitus e do illusio, como apontado por Bourdieu. Se para o francês há uma naturalização de ações e uma crença no desinteresse, a condição de um agente no interior de um campo é que seja internalizado um comportamento de que publicar é o caminho "mais correto" a ser seguido. Não apenas publicar. A comunicação científica deve ocorrer em veículos que possam alcançar o maior número de espectadores possíveis, alavancando as chances de difusão dos achados e, por conseguinte, o reconhecimento, o prestígio por ele.

\section{Considerações finais}

Entender, apoiados em Bourdieu (2012), que a construção de poder gira em torno das palavras é uma crença na instituição da palavra, do escrito, da fonte. Isso está ligado ao lugar de fala, na autoridade instituída e que declara elementos que são condicionantes de uma atividade. No entanto, o que devemos apreender é que a verdade e o poder não estão circunscritos exclusivamente às palavras, podendo estas compreenderem a atuação como meios, como dispositivos de reprodução de um tipo de credo social.

As decisões no campo científico sempre envolvem a dualidade política e científica; as escolhas feitas pelos agentes estão baseadas em interesses; ou ainda em atos de desinteresse como forma de reprodução da ordem social já estabelecida. O bom cientista é cínico, apostador de fichas em escolhas promissoras. Por essa lógica, a publicação em revistas científicas tende a ser sistematizada de forma vertical.

O acesso aberto, então, poderia agir como um campo de barreira, impondo seus limites para que seja possível não aceitar influências externas, ou seja, mantendo alta capacidade de refração. Deve, como isso, buscar estratégias - no sentido bourdieusiano - dentro do próprio campo para que essa captação de capital seja fluida tanto na esfera temporal quanto específica. Isso pode facilitar, inclusive, que agentes públicos financiadores das pesquisas tenham acesso às informações que possam subsidiar novos empreendimentos de pesquisa. 
Como dissemos, na perspectiva de Bourdieu, isso formaria um campo com suas estruturas estruturantes constituídas a partir desse modelo de comunicação científica, com forças, lutas e distinções, não havendo uma extenuação do campo da comunicação científica. Um campo é recoberto de uma ordem social constantemente reproduzida. Os não iniciados enxergam apenas o caos. Caos, nesse sentido, é algo que não comporta o conhecimento do estrangeiro, uma vez que a ordem que existe no caos, para o desconhecedor, compreende apenas desordem.

Há de se entender, por fim, que os aspectos que incluem as análises sobre as ações de um coletivo passam por estudos culturais, de campo, de ideologias etc. Ou seja, são estruturas que, a partir de elementos sociais e cognitivos, buscam padrões históricos, da experiência do ser. Nossa questão está em buscar o estudo dessas ideias vinculadas à comunicação científica, a partir do que vislumbramos como uma crise no acesso à informação.

\section{Referências}

ARENDT, H. A condição humana. 12. ed. Rio de Janeiro: Forense Universitária, 2014.

BONNEWITZ, P. Primeiras lições sobre a sociologia de P. Bourdieu. Petrópolis: Vozes, 2003.

BOURDIEU, P. A distinção: crítica social do julgamento. Porto Alegre: Zouk; São Paulo: EDUSP, 2006.

BOURDIEU, P. Algumas propriedades dos campos. In: BOURDIEU, P. Questões de sociologia. Lisboa: Fim de Século, 2003.

BOURDIEU, P. O poder simbólico. Rio de Janeiro: Bertrand Brasil, 2012.

BOURDIEU, P. Os usos sociais da ciência: por uma sociologia clínica do campo científico. São Paulo: UNESP, 2004.

BOURDIEU, P. Razões práticas: sobre a teoria da ação. 11. ed. Campinas: Papirus, 1996.

CASTORIADIS, C. A instituição imaginária da sociedade. 3. ed. Rio de Janeiro: Paz e Terra, 1995. 
LÉVY, P. O que é virtual? Rio de Janeiro: Editora 34, 1996.

LIZARDO, O. Pierre Bourdieu as a post-cultural theorist. Cultural Sociology, Thousand Oaks, v. 5, n. 1, p. 1-22, Mar. 2011.

OLIVEIRA, P. P. Illusio: aquém e além de Bourdieu. Mana, Rio de Janeiro, v. 11, n. 2, p. 529-543, 2005.

VANTI, N.; COSTA, J. A. F.; SILVA, I. C. O. Nova fórmula revisada para o cálculo do fator de impacto WEB (FIW). Liinc em Revista, Rio de Janeiro, v. 9, n. 1, p. 228-236, maio 2013.

WACQUANT, L. Esclarecer o habitus. Educação \& Linguagem, São Paulo, v. 10, n. 16, p. 63-71, jul./dez. 2007.

\title{
Agradecimentos
}

Agradecemos as sugestões dos avaliadores.

\section{Bourdieusian approach to an analysis of field: a focus to scholarly communication and open access}

\begin{abstract}
The work aims to understand the bourdieusian concepts like field, habitus and illusio to undertake subsidies reflections related to access to scientific knowledge. It presents qualitative methodology and bibliographic approach from works dealing with the concepts systematized by Pierre Bourdieu. Believes that decisions in the scientific field involve the political and the scientific duality and that the choices made by agents are based on symbolic interests. Ends guided by open access as a possibility to be a barrier field, imposing its limits to not accept external influences such as economic capital.
\end{abstract}

Keywords: Pierre Bourdieu; Field; habitus; illusio; Scholarly communication.

Recebido em: 21/09/2016

Aceito em: 12/12/2016 
Abordagem bourdieusiana para uma análise de campo: um enfoque para a comunicação científica e o acesso aberto

Jackson da Silva Medeiros

${ }^{1}$ O virtual não é uma oposição ao real, mas um "[...] complexo problemático [...] de forças que acompanha[m] uma situação, um acontecimento, um objeto ou uma entidade qualquer [...]." (LÉVY, 1996, p. 16). Isto é, caracteriza-se pelo espaço potencial que o acontecimento pode ser.

${ }^{2}$ Não pretendemos buscar ou entrar em definições sobre "ciência". Além disso merecer um estudo próprio e aprofundado, não é o objetivo deste trabalho e trazer essa ideia aqui está colocada em caráter de exemplificação.

${ }^{3}$ Entendemos que a relação de justificativas entre a demanda social e a demanda científica é uma associação a ser investigada. No entanto, foge do escopo de nosso trabalho. 